\title{
Automatic recording of daily walkover liveweight of dairy cattle at pasture in the first $\mathbf{1 0 0}$ days in milk
}

\author{
J. I. Alawneh, ${ }^{\star 1}$ M. A. Stevenson, ${ }^{*}$ N. B. Williamson, $\nmid$ N. Lopez-Villalobos, $\nmid$ and T. Otleył \\ *EpiCentre, Institute of Veterinary, Animal and Biomedical Sciences, and \\ †Institute of Veterinary, Animal and Biomedical Sciences, Massey University, Palmerston North 4442, New Zealand \\ $\ddagger$ Tru-Test New Zealand, PO Box 51078, Pakuranga 2140, New Zealand
}

\section{ABSTRACT}

Daily walkover liveweight (WoLW) records ( $\mathrm{n}=$ 79,697 ) from 463 pasture-fed dairy cows from a single dairy herd in the lower North Island of New Zealand were recorded over the first $100 \mathrm{~d}$ of lactation. The aims of this study were to (1) describe LW records retrieved by a standalone automatic Wo daily weighing system; (2) describe the frequency and nature of outlier LW records measured by the system and develop an approach for excluding identified outlier LW records; (3) quantify the agreement between cow LW measured using the Wo system and those measured statically; and (4) describe the autocorrelation between daily LW measurements to provide an indication of how frequently management decisions need to be reviewed to effectively monitor cow LW change in the early-lactation period. The standard deviation of daily LW measurements across parities was $17 \mathrm{~kg}$, on average. A near perfect association between LW measured statically and WoLW (concordance correlation coefficient $0.99,95 \%$ CI $0.99-1.0$ ) was observed. After controlling for the effect of LW at calving and long-term LW change using a mixed-effects linear regression model, the autocorrelation between WoLW recorded on successive days was 0.21 , decaying to zero by $8 \mathrm{~d}$. This study shows that by using a standalone automatic Wo weighing system positioned in the exit race of a rotary milking parlor, it was possible to record LW of individual cows on a daily basis and, with controlled cow flow over the weighing platform (allowing for sufficient succession distance to prevent congestion), results were similar to those recorded using conventional, static weighing techniques using the same scales. Based on the autocorrelation analyses, we recommend that LW are recorded on a daily basis to allow changes in physiological status such as the onset of acute illness or estrus to be detected. For managerial purposes, such as using LW change as a guide for adjusting the herd

Received November 11, 2010.

Accepted May 10, 2011.

${ }^{1}$ Corresponding author: j.alawneh@massey.ac.nz feeding program, we recommend a 7-d decision interval to effectively monitor significant changes in cows' recorded daily LW measurements.

Key words: automatic walkover weighing, daily liveweight, concordance, dairy cattle

\section{INTRODUCTION}

Economic drivers of milk production in New Zealand have resulted in an increase in the national median herd size and a decrease in the number of labor units per cow. In 2008 to 2009, the median milking herd size was 300 cows and the average number head of cattle managed per labor unit was 150 (LIC and DairyNZ, 2009). Under these conditions, successful dairy farming is less dependent on the husbandry of individual animals and more dependent on the ability of farm staff to manage large numbers of animals at the population or group level (Ott et al., 1995).

Several technologies are now available to assist dairy herd staff to manage large numbers of stock. Automated systems are available to manage feed (McAllister et al., 2000), milking (Growsafe, Growsafe Systems Ltd., Airdrie, Alberta, Canada; DeLaval feeding stations, DeLaval International, Tumba, Sweden), and estrus detection (HeatWatch; DDx Inc., Denver, CO). These technologies have the potential to enhance herd profitability by identifying shortfalls in performance or impending problems without requiring a herd manager to scrutinize herd data in detail at regular intervals. They also allow problems to be detected promptly, which means that corrective action can be taken in a timely manner (Peiper et al., 1993; Spahr and Maltz, 1997; Cveticanin and Wendl, 2004).

Measurement of liveweight $(\mathbf{L W})$ is an established method for monitoring the performance of intensive and extensively managed beef cattle (Clanton et al., 1983). Individual animal LW and estimates of LW change have relatively recently been used as tools to aid in the management of dairy herds (Spahr and Maltz, 1997; Robinson, 2005). Changes in body composition and LW have been associated with dairy cow health (Berry et 
al., 2007a), fertility (Buckley et al., 2000), milk yield, and milk composition (Maltz et al., 1997; Berry et al., 2007b; Roche et al., 2007a). Berry et al., (2007a) studied LW and LW change and its association with clinical mastitis in 2,600 lactations in 897 New Zealand dairy cows and reported a negative association between LW change and clinical mastitis. These authors found that cows that lost a greater amount of weight postpartum (1 SD below mean LW loss across the entire lactation) had a 1.29 (95\% CI 1.02-1.64) times increase in the odds of clinical mastitis occurring throughout the lactation. Roche et al. (2007a) used the same data to identify and quantify relationships between LW change and reproductive performance. They reported that the odds of detecting estrus after the planned start of mating (PSM) date was positively associated with LW change and cows that lost more weight from calving to the nadir (minimum LW recorded for each cow) or PSM were less likely to be detected in estrus and be submitted for $\mathrm{AI}$ in the first $21 \mathrm{~d}$ following the PSM.

Liveweight measurements in dairy cattle are typically obtained using conventional static weighing systems, which require cattle to be individually walked onto a set of scales and a measurement recorded when the system comes to equilibrium. This process is time consuming, labor intensive, and places stress on both the animals being weighed and the operator carrying out the procedure (Charmley et al., 2006). Walkover (Wo) weighing systems require cattle to pass through a specially designed crate, which allows body mass to be estimated using continuous averaging techniques (Long et al., 1991, Ren et al., 1992; Peiper et al., 1993). In commercial dairies, Wo scales provide several advantages over static methods, as LW can be measured frequently (e.g., at the end of each milking) without the stress associated with conventional weighing procedures. Such measurements can then be used as a proxy to assess the physiological well-being of individual herd members. Little appears to be known about how WoLW measurements agree with static LW measurements under commercial dairy farm conditions and how daily WoLW measurements can be turned into useful information that could be used for diagnostic (e.g., detecting temporary states or disorders, such as estrus or disease) or managerial purposes (e.g., feeding cows according to performance or to prevent undesired LW loss).

Although WoLW facilities show great promise in providing information that can be used for tactical and strategic herd management, poor cow flow over the scale platform (resulting in more than 1 cow simultaneously being present on the scale platform, or a cow standing partially on the scale platform at a given time) can result in erroneous LW measurements, manifest as outliers in the data presented for analysis (Filby et al., 1979). A critical issue when analyzing data collected using these systems relates to the decision rules around how far an animal's recorded weight needs to change from previous values before it should be regarded as erroneous. Outlier detection in this situation consists of 2 problems: first, defining which data are exceptionally distant from other values in a given data set and, second, finding an efficient algorithm to deal with such data (Han, 2006). The majority of WoLW studies in dairy cattle contain few details about the methodology used to detect and deal with outlying observations and simply refer to these observations as biologically implausible (Ren et al., 1992; Pastell et al., 2006; Kujala et al., 2008). A small number of studies have addressed the problem in detail. van Straten et al., (2008) used a technique involving penalized cubic spline regression methods and time series analyses to avoid outlying LW measurements from 3,295 zero-grazing, high-producing Israeli Holsteins. Onyiro et al., (2008) studied 14,026 LW records from 248 Holstein-Friesian cows in Scotland and used observation distance (expressed in terms of the number of standard deviations from a cow's mean LW) to identify and remove LW records that were considered biologically implausible.

With this background, the objectives of this study were to evaluate a WoLW system on a commercial New Zealand dairy farm. Specifically, our aims were to (1) describe LW records retrieved by a standalone automatic Wo daily weighing system over the first 100 DIM in a single seasonally calving, pasture-fed New Zealand dairy herd; (2) describe the frequency and nature of outlier LW records measured by the system and develop an approach for excluding identified outlier LW records; (3) quantify the agreement between cow LW measured using the Wo system and those measured statically; and (4) describe the autocorrelation between daily LW measurements to provide an indication of how frequently management decisions need to be reviewed to effectively monitor cows LW change in the earlylactation period.

\section{MATERIALS AND METHODS}

\section{Study Animals}

This was a prospective cohort study of $n=463$ mixed aged and breed (Holstein-Friesian, Jersey, and HolsteinFriesian $\times$ Jersey crossbreeds) dairy cows that calved between July 15 and October 24, 2008 in a seasonally calving, pasture-fed dairy herd in Palmerston North in the lower North Island of New Zealand (longitude $175^{\circ}$, latitude $-40^{\circ}$ ). Cows grazed as a single herd and had free access to water. The herd was managed so that the 


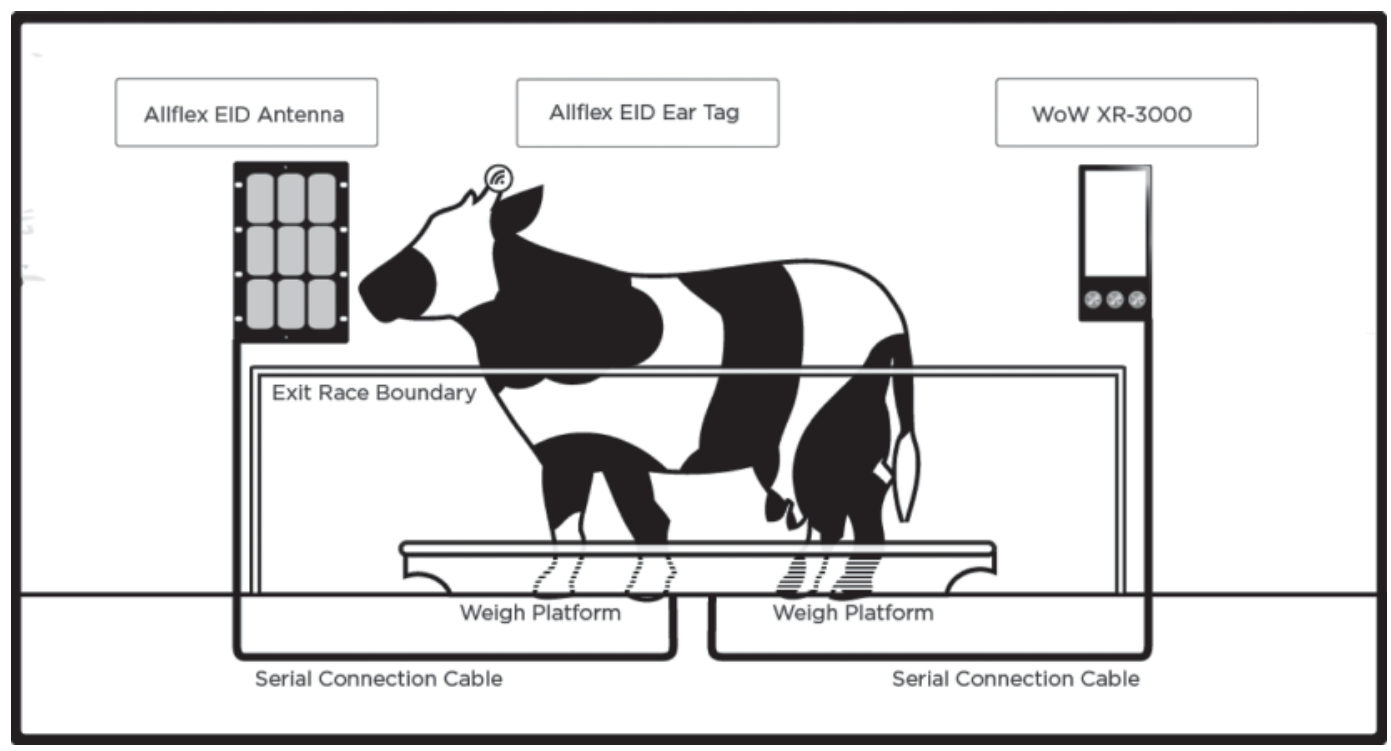

Figure 1. Diagram showing the hardware configuration used in this study. Allflex electronic identification (EID) ear tag and antenna, Allflex New Zealand Ltd., Palmerston North, New Zealand. WoW XR-3000, Tru-Test Ltd., Auckland, New Zealand.

pasture allowance and access to supplementation after the morning milking (palm kernel meal to a maximum of $2 \mathrm{~kg}$ of $\mathrm{DM} /$ cow per day and maize silage to a maximum of $2 \mathrm{~kg}$ of $\mathrm{DM} /$ cow per day) was sufficient for maintenance and production requirements of a $400-\mathrm{kg}$ LW cow producing $2.0 \mathrm{~kg}$ of milk solids/d. Cows were milked twice daily, starting at 0530 and $1500 \mathrm{~h}$, in a rotary platform milking parlor (DeLaval parallel rotary; DeLaval International).

Cows were identified using a radio frequency electronic identification (EID) system. This was composed of low-frequency (134.2 kHz), high-performance, nonreusable half duplex ear tags fitted to each cow and an antenna (Allflex; Allflex New Zealand Ltd., Palmerston North, New Zealand). The antenna was connected via a serial connection cable (9 pin universal RS232 connector cable) to an electronic Wo scale system composed of an aluminum Wo platform, 2 electronic load bars and a scale indicator (Tru-Test Ltd., Auckland, New Zealand; Figure 1). The antenna and Wo scale system were installed in the exit race, $10 \mathrm{~m}$ away from the exit point of the milking platform. Liveweights were recorded as each cow walked away from the milking platform at the end of each milking. Because this was an observational study, and 1 of our objectives was to determine the proportion of outlier records, no direct interventions were applied throughout the study period to interfere with, or modify cow flow over the scale platform. The Wo scale system was calibrated to have an accuracy of $\pm 2 \mathrm{~kg}$. The study period was from July 15, 2008 to February 1, 2009 (100 d after the last cow in the herd calved for the 2008-2009 milking season).
Throughout the study period LW data were downloaded from the scale indicator to a portable personal computer twice weekly. Downloaded data included each cow's electronic identifier, the date and time of each weigh event, and the LW measurement (in kilograms) as estimated by the scales. Data were transferred to a dairy herd management software package (DairyWin v99.91.148; Massey University, Palmerston North, New Zealand) allowing LW data to be matched with each cow's biographical and lactation event details (e.g., calving date, insemination date(s), and diagnosis and treatment details and dates).

To quantify the agreement between LW measured using the Wo system with those measured statically, 3 groups of animals were weighed on August 4, 2008; September 1, 2008; and October 6, 2008. On each of these dates, the last 50 cows milked at the morning milking were allowed to walk freely (allowing for sufficient succession distance to prevent congestion) over the scale platform and then immediately re-drafted for static LW measurement. For the static weights, the same set of scales was used with the Wo weigh function disabled. The time period when this subgroup was held and re-weighed was kept to a maximum of $1 \mathrm{~h}$.

\section{LW Data Management}

Prior to analysis a series of data cleaning procedures were carried out. First, outlier individual LW records were considered to fall into 1 of 2 categories: (1) those that were biologically implausible and (2) those, although biologically plausible, were extreme for a given 
animal (termed potentially erroneous records in the remainder of this paper).

Second, we generated a smoothed LW curve using a nonparametric cubic spline regression model for each cow (Figure 2). This approach used DIM as a single smoothing variable. The smoothed value for a given DIM was calculated by minimizing the following quantity:

$$
Q(\alpha)=\sum_{i=1}^{n}\left[y_{i}-\mu\left(t_{i}\right)\right]+\alpha \int_{-\infty}^{\infty}\left[\mu^{\prime \prime}(t)\right]^{2} \mathrm{~d} t
$$

In Equation 1, $y_{i}$ is the individual LW record on $\mathrm{DIM}_{i}$, $\mu\left(t_{i}\right)$ is a cubic function of $\mathrm{DIM}_{i}$, and $\alpha$ is a term to define the trade-off between the closeness of fit to the data as measured by the residual sum of squares and smoothness of $\mu(t)$ as measured by the integral term (the squared second derivative of the cubic function, Diggle, 1990, p. 27). The trade-off between goodness of fit and smoothness $(\alpha)$ that minimized the predictive residual sum of squares on the fitted data was determined using a generalized cross-validation procedure (Green, 1994), implemented using the smooth spline

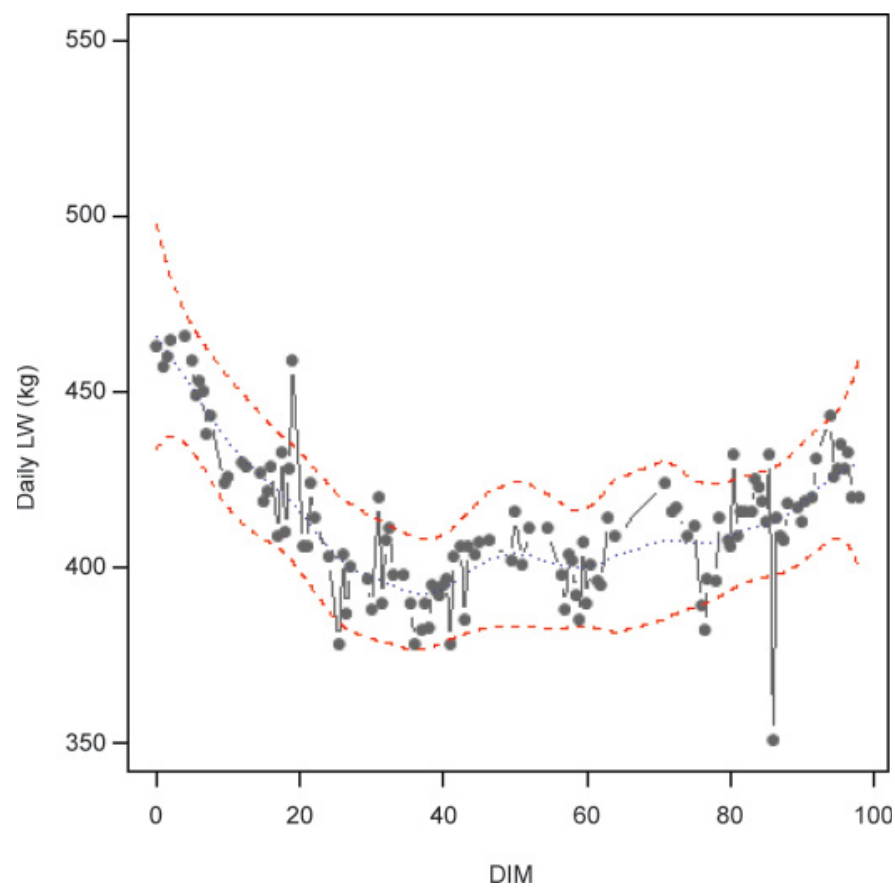

Figure 2. An example of the outlier detection method used in this study. Individual liveweight (LW) records for 1 cow are shown as points $(\bullet)$. The dotted line shows a penalized cubic regression line fitted to individual LW records. The dashed lines represent the lower and upper $95 \%$ prediction intervals around the penalized cubic regression line. Six potentially erroneous individual LW records and 1 biologically implausible individual LW record were identified at 20, 25, 30, 40, 75 79 , and 85 DIM, respectively. The standard deviation for this cow calculated from the raw data (0-100 DIM) was $15 \mathrm{~kg}$. Color version available in the online PDF. function within $\mathrm{R}$ version 2.10.0 (R Development Core Team, 2010). Individual LW records on $\mathrm{DIM}_{i}$ were identified as biologically implausible from a cow's set of individual LW records if they varied by more than 4 standard deviations (calculated using each cow's individual LW records between 0 to 100 DIM) above or below the estimated LW at $\operatorname{DIM}_{i}$ (Figure 2). This approach identified those individual LW records where less than a $1 \%$ chance existed that they were plausible values for that DIM. Finally, an individual LW record on DIM was then identified as potentially erroneous if it was above or below the boundaries of the $95 \%$ prediction intervals calculated around the estimated smooth daily LW curve (Figure 2). This approach identified those individual LW records where less than a 5\% chance existed that they were plausible values for that DIM. To minimize the variation of LW that could arise from differences in daily gut fill effects, feed management or availability and milk volume between milking sessions, the 2 individual LW records for each cow for each day were averaged to provide a single daily measurement. If 1 record was missing (11\% of total records) the remaining record was used. In the remainder of this paper, we use the term daily LW measurement to refer to the averaged daily individual LW records.

Individual cow LW at calving was quantified by averaging daily LW measurements during the first $7 \mathrm{~d}$ after the date of parturition. Our reason for doing this was to enhance the precision of the estimate of LW at calving, as erratic cow flow over the scale platform was more common early in the season when large numbers of freshly calved cows joined the milking herd. The day of nadir LW for each member of the herd was defined as the DIM when minimum LW was recorded and was identified using a 2-step process. First, the daily recorded LW for each cow were converted into weekly averages and records were screened to determine the week in milk with the minimum average LW. Second, the DIM within the selected week with the lowest LW was taken as the nadir LW day. Liveweight change from calving to nadir was derived by subtracting the LW recorded at the nadir DIM from the recorded LW at calving (positive values representing losses and negative values representing gains). Also, the LW change from calving to 100 DIM (the end of the study observation period) was calculated by subtracting the LW recorded at 100 DIM from the recorded LW at calving (again, positive values representing losses and negative values representing gains).

\section{Statistical Analyses}

Differences in mean LW at calving, mean LW loss to nadir and mean days to nadir LW across different pari- 
ties (first to second parities, third to fourth parities, and fifth and greater parities) and adjusted for breed were evaluated by ANOVA within the structure of a general linear model. The significance of the source of variation was determined using the F-test for type III sum of squares. This approach was used due to the unbalanced nature of the data.

An evaluation of the level of agreement between WoLW and LW measured statically was made using Lin's concordance correlation coefficient (Lin, 1989, 2000). The concordance correlation coefficient combines measures of both precision and accuracy to determine how far the observed data deviate from perfect concordance (a concordance correlation coefficient of 1.0). A limit of agreement plot (Bland and Altman, 1995) was used to directly compare Wo and static LW measurements.

Because LW measurements can be used in several different ways (e.g., for monitoring responses to feeding programs versus detecting adverse health events in individual cows), it follows that the frequency of recording and analyzing weigh events might need to vary, depending on specific management objectives. For this reason, it was of interest to determine the number of days that must elapse between weigh events for a change in LW to be detected. To address this objective we developed a linear mixed model that accounted for individual cow-level effects (that is, LW at calving and change in LW postcalving) using the following model:

$$
y_{i j}=\beta_{0}+\beta_{1} t_{i}+\beta_{2} t_{i}^{2}+\alpha_{j 0}+\alpha_{j 1} t_{i}+\alpha_{j 2} t_{i}^{2}+\varepsilon_{i j} .
$$

In Equation 2, $y_{i j}$ is the LW of cow $j$ at DIM $t_{i} ; \beta_{0}$, $\beta_{1}, \beta_{2}$ are regression coefficients to estimate LW as a function of DIM at the herd level; $\alpha_{j 0}, \alpha_{j 1}$, and $\alpha_{j 2}$ are random intercept and slope terms to describe the deviation of the LW of cow $j$ from that of the herd at $\mathrm{DIM}_{i}$; and $\varepsilon_{i j}$ represents the model residuals, the difference between LW predicted from the fixed and random regression coefficients and the LW actually recorded for cow $j$ at DIM $t_{i}$.

An autocorrelation function (ACF) plot was constructed to show the correlation between the model residuals after adjusting for the covariates presented in Equation 2 at each distinct time separation or lag $\left|\mathrm{DIM}_{k}-\mathrm{DIM}_{l}\right|$, where $k<l$ (Diggle, 2002). By doing this, we were able to quantify the similarity in LW measurements at given time separations after controlling for the size of the cow (through the random intercept term) and long-term weight change that might occur after calving (through the random slope). These analyses were performed using the REML procedure implemented within the nlme package (Pinheiro et al., 2008) in R.

\section{RESULTS}

A total of 79,697 individual LW records available for analysis. Of these, 9,298 (12\%) LW records were defined as outliers (Table 1). Daily individual LW records that were above and below the $95 \%$ prediction intervals calculated around the estimated smooth daily LW curve using the cubic spline method ranged from 0 to $465 \mathrm{~kg}$. Outliers were excluded from the data set before further analyses were conducted. A summary of the individual LW records and daily LW measurements are shown in Table 1.

The distribution of daily LW measurements was consistent with the normal distribution (KolmogorovSmirnoff test of normality $P<0.05)$. Liveweights at calving differed significantly across parities $(P<0.05)$. The standard deviations of daily LW measurements across parities were $17 \mathrm{~kg}[(17 / 395) \times 100=4.3 \%]$, $16 \mathrm{~kg}[(16 / 440) \times 100=3.6 \%]$, and $17 \mathrm{~kg}[(17 / 526) \times$ $100=3.2 \%$, for first and second, third and fourth, and fifth or greater parities, respectively. First- and secondparity LW loss at the nadir (44 kg) and 100 DIM (13 $\mathrm{kg}$ ) compared with LW at calving were significantly lower $(P<0.05)$ than those recorded for the third and fourth $(52 \mathrm{~kg}, 26 \mathrm{~kg})$, and fifth or greater parities (62 $\mathrm{kg}, 30 \mathrm{~kg})$.

Figure 3 and Figure 4 show the concordance and the agreement between Wo and statically recorded LW measurements for 3 subgroups $(\mathrm{n}=50)$ of cows weighed in August, September, and October of 2008. As shown in Figure 3, the best linear fit was $y=1.005 x$, where $y$ is the measured WoLW and $x$ is the statically measured LW ( $\mathrm{R}^{2}$ 0.9982). The concordance correlation coefficient was 0.99 (95\% CI 0.99-1.00). Figure 4 shows that the errors were randomly scattered around the mean throughout the entire weight range, and overall, the mean difference between Wo and static LW was $-2.3 \mathrm{~kg}$ (SD $3.2 \mathrm{~kg}$ ). The $95 \%$ lower and upper limits of agreement were $-8.8 \mathrm{~kg}$ and $+4.2 \mathrm{~kg}$, respectively.

The ACF plot (Figure 5) showed a moderately high autocorrelation of 0.21 at lag (d) 1 that decayed to zero by lag 8 . This means that, after controlling for individual cow-level effects (including LW at calving and LW change after calving), LW measured on a given day were unlikely to be correlated with LW measurements taken up to $7 \mathrm{~d}$ previously.

\section{DISCUSSION}

Our estimates of average LW at calving and LW loss from calving to nadir were in agreement with those reported by Roche et al. (2007b) in a study of 2,600 lactations in 897 New Zealand dairy cows. Roche et al. (2007b) reported a shorter number of days to nadir 
Table 1. Descriptive statistics of individual liveweight (LW) records and daily LW measurements of dairy cattle from a single pasture-fed dairy herd in the lower North Island of New Zealand, July 15 to October 24, 2008, stratified by parity groups $(\mathrm{n}=463)$

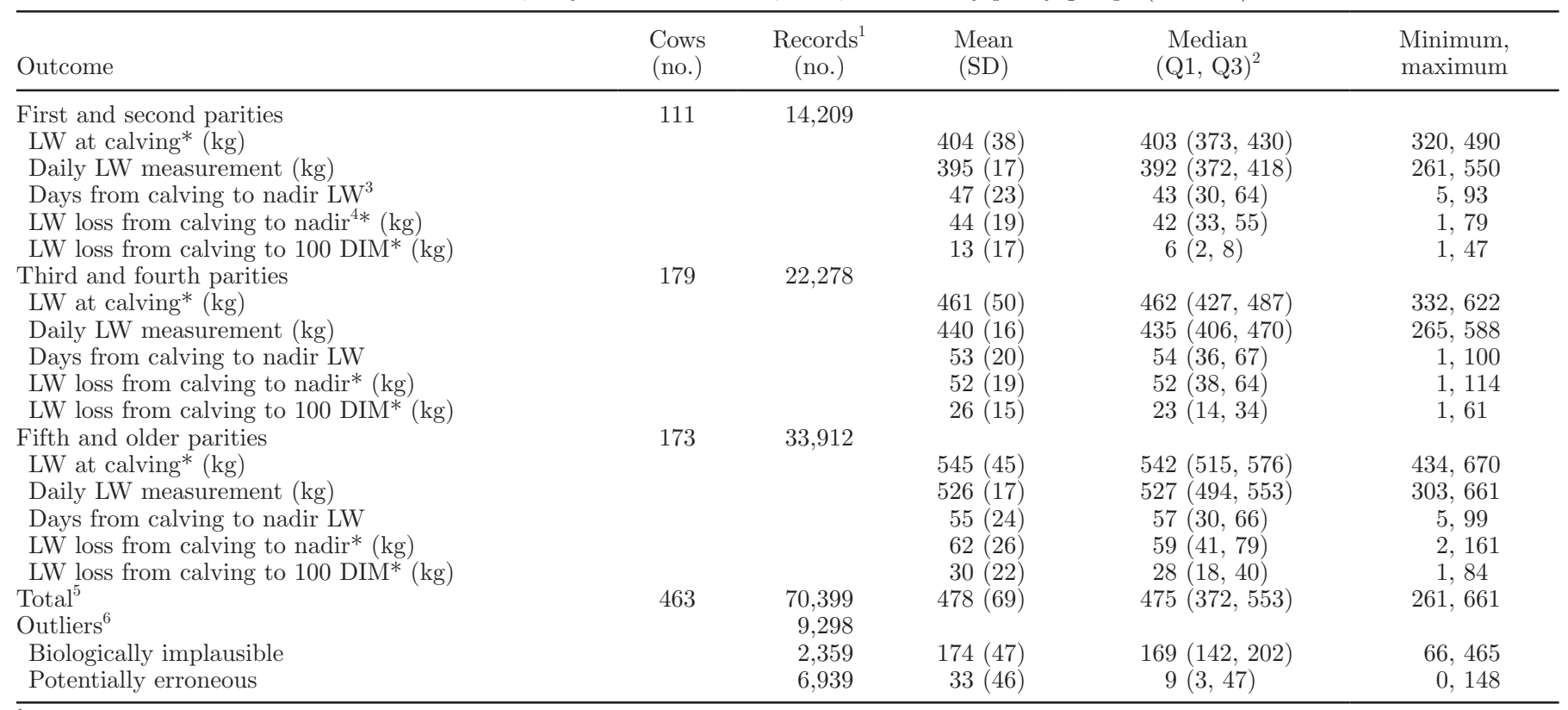

${ }^{1}$ Number of individual LW records (a.m. and p.m.), excluding (biologically implausible and potentially erroneous) outliers. Summary statistics were generated after outliers were excluded.

${ }^{2} \mathrm{Q} 1$ and Q3 are the twenty-fifth and seventy-fifth quantile, respectively.

${ }^{3}$ Day of nadir LW was the DIM where minimum daily LW measurement was recorded.

${ }^{4} \mathrm{LW}$ change from calving to nadir: LW at calving minus daily LW measurement at nadir. Positive values represent LW loss and negative values represent LW gain.

${ }^{5}$ Summary statistics based on total daily LW measurements excluding (biologically implausible and potentially erroneous) outliers.

${ }^{6}$ All individual LW records identified as biologically implausible and potentially erroneous outliers (a.m. and p.m.), as described in the text.

${ }^{*} P<0.05$ across the 3 parity groupings.

LW (30, 26, and $29 \mathrm{~d}$ for first-, second-, and greaterthan-second-parity cows, respectively) than seen in this study (Table 1). Our results show that the magnitude of weight loss, and therefore, degree of negative energy balance was less in first- and second-parity cows compared with cows of parity 3 or greater, a conclusion cited by other authors (de Vries and Veerkamp, 2000; van Straten et al., 2008).

Across parities, daily LW standard deviation represented 3.2 to $4.3 \%$ of mean daily LW measurement. This reported daily variation is greater than that previously reported in the literature. Maltz et al. (1997) used similar weighing technology to obtain daily LW for 24 Holstein dairy cows in the Netherlands. These authors reported that within-cow daily LW variation was 1 to $2.4 \%$. Peiper et al. (1993), in an earlier study, reported a $1.5 \%$ within-cow daily variation in a $3-y r$ study to determine the efficacy of recording LW using a walkthrough weighing system in 85 Israeli Holsteins. The variability observed in our study can be explained by the difference in weighing frequency in these studies (24 animals weighed 20 times per day and 85 animals weighed 3 times daily, respectively). Furthermore, vari- ability can also be explained by differences in management and feeding systems; a zero grazing and freestall system in the first and second study, respectively, versus the free-range, pasture-based system in our study. In dairy systems where cows are permitted to freely graze at pasture, the greater variability in daily LW measurements is likely to be a consequence of a range of factors, including individual animal eating behavior, the quantity and quality of available forages, water availability, and the distance cows have to travel to and from paddocks for grazing (Maltz et al., 1997).

We identified a near perfect association between LW measured using the WoLW system and those measured statically when cow flow over the platform was controlled (Figure $3 ; r^{2}=0.998$ ). The $95 \%$ limits of agreement show that LW measured using WoLW may be $4.2 \mathrm{~kg}(60 \%$ of recorded WoLW) above or $8.8 \mathrm{~kg}$ (40\% of recorded WoLW) below those recorded statically. Care is required when interpreting these results because although statically recorded LW are thought to be the best weighing method, it is neither an absolute or definitive measure of actual LW. Fecal and urinary losses that occurred between each weigh event 


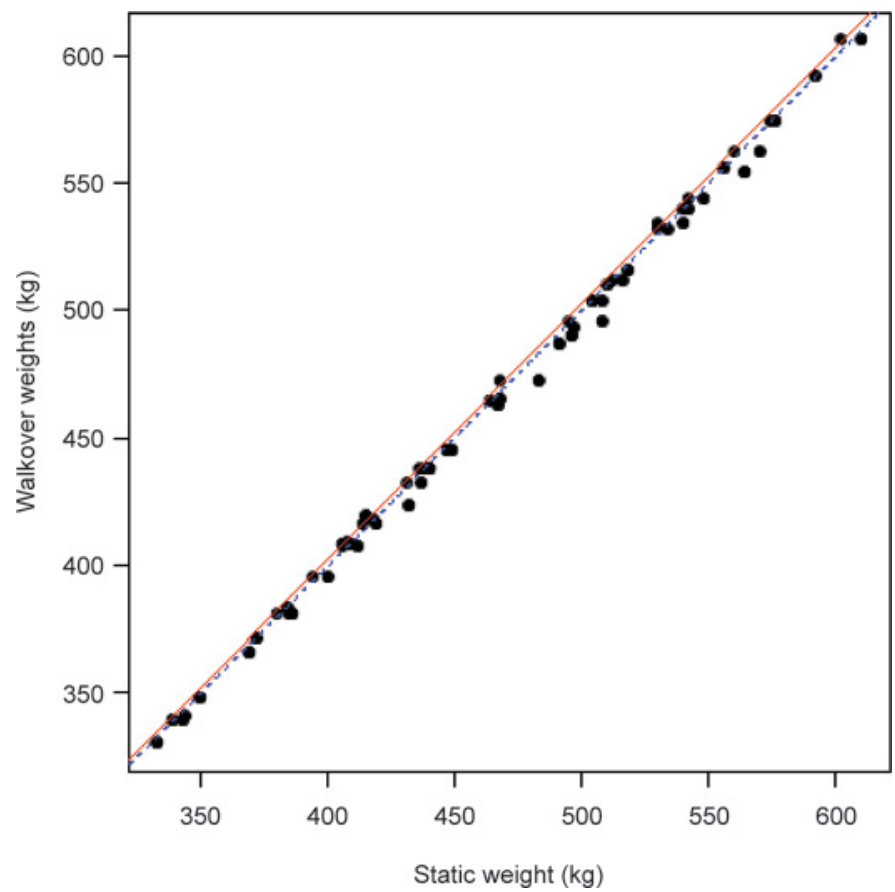

Figure 3. Static liveweight (LW) measurements versus walkover LW (WoLW) measurements of multiple groups of 50 cows weighed in August, September, and October of 2008. The broken line indicates the line of perfect concordance. The solid line is the best linear fit, $y$ $=1.005 x$, where $y$ is the measured WoLW and $x$ is the statically measured LW. The concordance correlation coefficient for these data was $0.99(95 \% \mathrm{CI}=0.99-1.00)$. Color version available in the online PDF

may partly explain why the WoLW differed from those recorded statically (in all cases in this study, WoLW were recorded first, then static LW). Another explanation could be linked directly to the time and speed of a cow crossing over the scale platform (Cveticanin, 2003; Cveticanin and Wendl, 2004). Walkover LW uses a continuous-averaging technique to estimate LW; thus, if a cow crosses the scale platform at high speed (in less than $2 \mathrm{~s}$ ) this will result in less data on which to base a LW estimate, with consequent effects on system accuracy.

The outlier detection method used in this study was a distance-based approach and relied on the absolute difference between an observed LW on $\mathrm{DIM}_{i}$ and the estimated LW based on the regression analyses described earlier. Once an outlier (i.e., biologically implausible or potentially erroneous) was identified, the absolute difference between the outlier at $\mathrm{DIM}_{i}$ and the boundary of the $95 \%$ prediction interval at $\operatorname{DIM}_{i}$ (Figure 2) was calculated to provide insight into the likely reason for the outlier's presence. Twenty-five percent $(2,359$ of 9,298 ) were classified as biologically implausible LW records. These observations were believed to be associated mainly with congestion in the exit race typically caused by first-parity heifers that had not fully ad- justed to the routine of entering and exiting the milking platform. The majority of WoLW outliers $(75 \%$; 6,939 of 9,298 ) was potentially erroneous LW records and ranged between 0 and $148 \mathrm{~kg}$ above or below the prediction interval boundary. Those were thought to be related to rapid cow flow over the weigh platform or due to a successor cow placing her forefeet on the platform while a leading cow was crossing over the platform, resulting in overestimation of the LW for the leading cow. Direct comparison of the outlier (i.e., biologically implausible and potentially erroneous) results reported here with findings from other studies was not possible due to the lack of information about the magnitude and frequency of outliers in the cited literature. To facilitate such comparisons, documenting the effect of animal behavior and management on the frequency of outliers would be encouraged in future studies.

The ACF plot shown in Figure 5 is based on the residuals from the model presented in Equation 2 and thus, represents the autocorrelation in daily LW measurements after controlling for the effect of size of the cow and long-term weight change that occurred after calving. The ACF plot (Figure 5) shows a progressive decay in the correlation between successive residual LW estimates over a period of $8 \mathrm{~d}$. The irregularity, particularly beyond the third lag, reflects short-term fluctuation in LW as a function of the number of days between LW measurements thought to be due to a combination of gut fill effects, cow milking order, or changes in animal physiological status, such as changes in physical activity associated with estrus or disease (Halachmi et al., 1997; Maltz et al., 1997; van Straten et al., 2009).

We propose that ACF plots have the potential to provide useful information for detecting abnormal weight change at the individual animal level. Based on these findings, we recommend that for identification of acutely ill cows, LW should be recorded and analyzed on a daily basis. For example, if an individual's residual LW at lag 1 or 2 differs excessively from that experienced by the remainder of the herd, then that cow should be investigated immediately, as it could be indicative of a severe physiological disorder (e.g., systemic illness or acute lameness). On the other hand, when using WoLW to aid decision making (for example, when adjusting the herd feeding program) our analyses show that (at least) a 7-d decision interval should be applied to monitor significant changes in cows' recorded daily LW measurements.

It is important that these findings are interpreted with caution, as they are only applicable for this herd. Similar to milk production, LW change is affected by management decisions that influence the animal and the environment. Replication of this study in a larger 

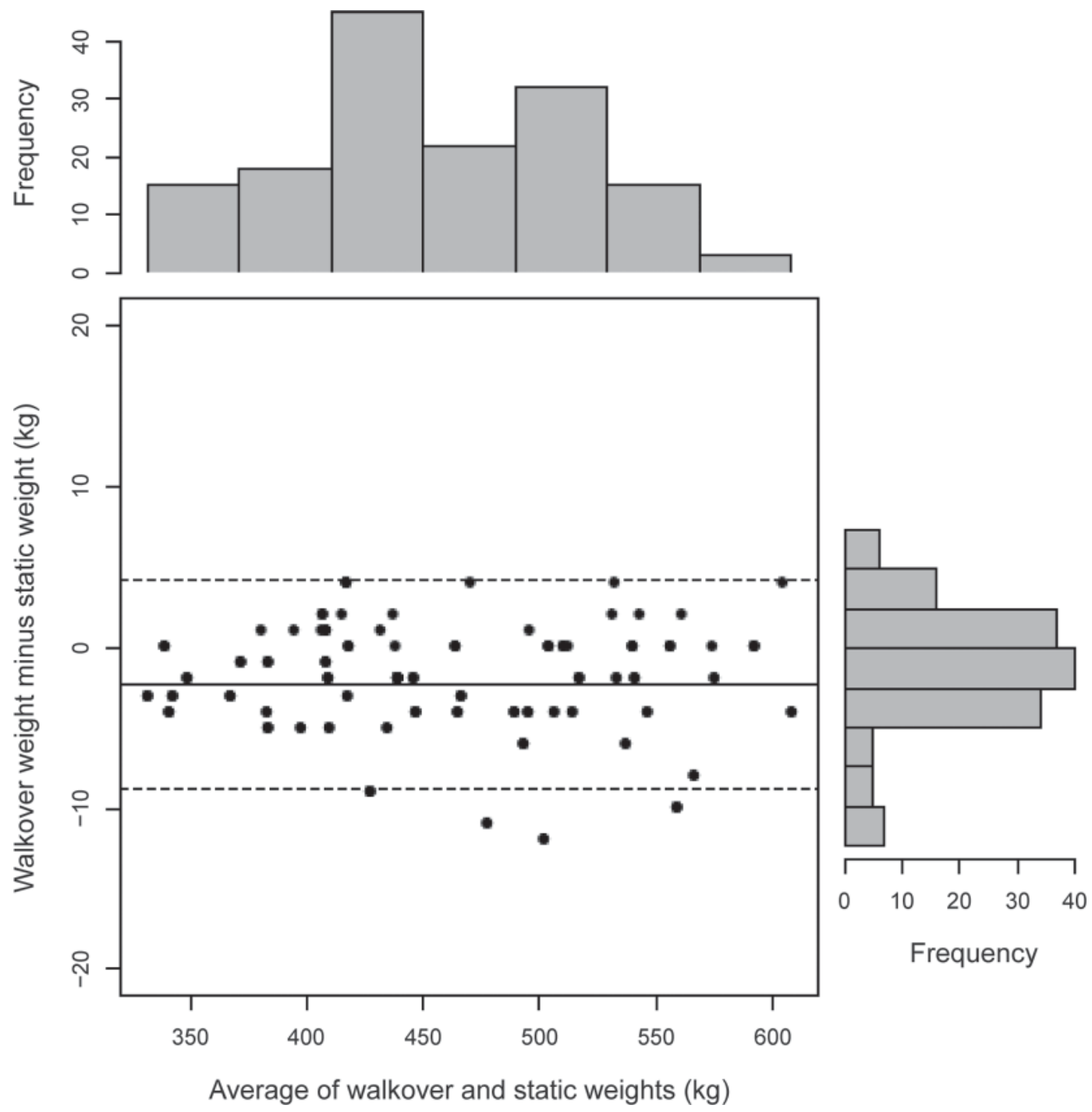

Figure 4. Walkover liveweight (LW) measurements versus static LW measurements from 3 groups of 50 cows weighed in August, September, and October of 2008. Scatter plot showing the observed difference between walkover and static LW (-) against the average of walkover and static weights. Also shows $95 \%$ limits of agreement ( -8.8 to $4.2 \mathrm{~kg}$ ) at 2 standard deviations (dashed lines) from the daily LW (solid line).

number of herds would be important to establish the external validity of the findings reported here. Of interest would be to establish if the observed residual autocorrelation estimates vary between and within herds over time (in response to, for example, herd size, feed management, and stocking rate). Also, it is worth noting that the number of outlying LW records was sensitive only to the cut-off point used for Equation 1. For example, a cut-off point of 2 standard deviations yielded approximately $27 \%$ of all LW measurements to be classified as outliers (results not shown) compared with the $12 \%$ reported here. The number of outliers decreased as the value of the cut-off point increased $(\mathrm{SD}=2.5,3.0,4.0)$. Our objective was to identify those LW measurements where less than a $1 \%$ chance existed that they were plausible values for that DIM; therefore, a 4 standard deviation cut-off value was used. If lower cut-off values such as 2 standard deviations were used, the method described in Equation 1 would be too sensitive and our ability to detect short-term changes in LW could be compromised.

\section{CONCLUSIONS}

This study addresses several issues that could potentially be an obstacle to more widespread uptake of WoLW technology in commercial, pasture-fed dairy herds. First, we have shown that with appropriate equipment and technology it is possible to record dairy cow LW on a daily basis throughout the early-lactation 


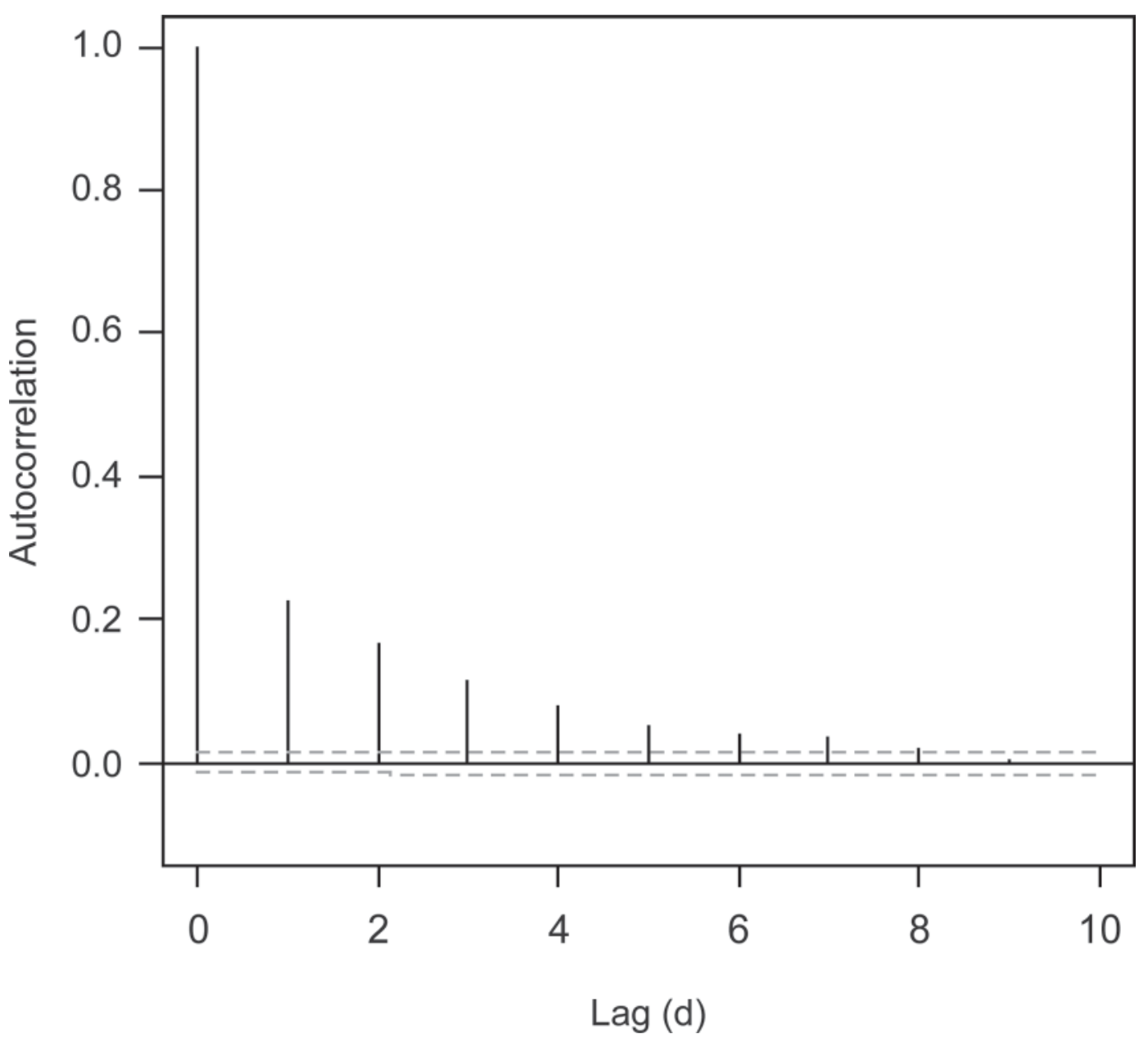

Figure 5. Autocorrelation function (ACF) showing the correlation in the raw residuals $\left(\varepsilon_{i j}\right)$ from Equation 2 as a function of number of days between successive daily liveweight measurements. Dashed gray lines represent approximate 2 -sided critical bounds for the autocorrelation at $\alpha=0.01$.

period. With controlled cow flow over the weighing platform a high level of agreement existed between LW, measured using Wo scales and those measured statically. Second, we have provided an algorithm to identify and eliminate outlier LW records, making it easier for herd managers to draw inferences from LW records gathered in real time. Finally, we quantified the residual temporal autocorrelation in daily LW measurements, providing a more objective basis for defining decision intervals when using daily LW measurements for diagnostic and managerial purposes.

\section{REFERENCES}

Berry, D. P., J. M. Lee, K. A. Macdonald, K. Stafford, L. Matthews, and J. R. Roche. 2007a. Associations among body condition score, body weight, somatic cell count, and clinical mastitis in seasonally calving dairy cattle. J. Dairy Sci. 90:637-648.

Berry, D. R., F. Buckley, and R. Dillon. 2007b. Body condition score and live-weight effects on milk production in Irish Holstein-Friesian dairy cows. Animal 1:1351-1359.
Bland, J. M., and D. G. Altman. 1995. Comparing methods of measurement: Why plotting difference against standard method is misleading. Lancet 346:1085-1087.

Buckley, F., P. Dillon, M. Rath, and R. F. Veerkamp. 2000. The relationship between genetic merit for yield and live weight, condition score, and energy balance of spring calving Holstein Friesian dairy cows on grass based systems of milk production. J. Dairy Sci. 83:1878-1886.

Charmley, E., T. L. Gowan, and J. L. Duynisveld. 2006. Development of a remote method for the recording of cattle weights under field conditions. Aust. J. Exp. Agric. 46:831-835.

Clanton, D. C., L. E. Jones, and M. E. England. 1983. Effect of rate and time of gain after weaning on the development of replacement beef heifers. J. Anim. Sci. 56:280-285.

Cveticanin, D. 2003. New approach to the dynamic weighing of livestock. Biosyst. Eng. 86:247-252.

Cveticanin, D., and G. Wendl. 2004. Dynamic weighing of dairy cows: Using a lumped-parameter model of cow walk. Comput. Electron. Agric. 44:63-69.

de Vries, M. J., and R. F. Veerkamp. 2000. Energy balance of dairy cattle in relation to milk production variables and fertility. J. Dairy Sci. 83:62-69.

Diggle, P. J. 1990. Time Series: A Biostatistical Introduction. Oxford University Press, Oxford, UK. 
Diggle, P. J. 2002. Analysis of Longitudinal Data. Oxford University Press, Oxford, UK.

Filby, D. E., M. J. B. Turner, and M. J. Street. 1979. Walk-through weigher for dairy-cows. J. Agric. Eng. Res. 24:67-78.

Green, P. J. 1994. Nonparametric Regression and Generalized Linear Models: A Roughness Penalty Approach. Chapman \& Hall, London, UK.

Halachmi, I., E. Maltz, J. Metz, and S. Devir. 1997. The body weight of the dairy cow. II. Modeling individual voluntary food intake based on body weight and milk production. Livest. Prod. Sci. 48:239-246.

Han, J. 2006. Data Mining: Concepts and Techniques. 2nd ed. Elsevier, San Francisco, CA.

Kujala, M., M. Pastell, and T. Soveri. 2008. Use of force sensors to detect and analyse lameness in dairy cows. Vet. Rec. 162:365-368.

LIC (Livestock Improvement Corp.) and DairyNZ. 2009. New Zealand Dairy Statistics 2008-09. Livestock Improvement Corp., Hamilton, New Zealand.

Lin, L. I.-K. 1989. A concordance correlation coefficient to evaluate reproducibility. Biometrics 45:255-268.

Lin, L. I.-K. 2000. A note on the concordance correlation coefficient. Biometrics 56:324-325.

Long, J., H. Takahata, K. Umetsu, H. Hoshiba, and I. Takeyama. 1991. A livestock walk-through scale system. J. Soc. Agric. Struct. 21:175-182.

Maltz, E., S. Devir, J. H. M. Metz, and H. Hogeveen. 1997. The body weight of the dairy cow. 1. Introductory study into body weight changes in dairy cows as a management aid. Livest. Prod. Sci. $48: 175-186$.

McAllister, T. A., D. J. Gibb, R. A. Kemp, M. E. Huisma, M. E. Olson, D. Milligan, and K. S. Schwartzkopf-Genswein. 2000. Electronic identification: Applications in beef production and research. Can. J. Anim. Sci. 80:381-392.

Onyiro, O. M., J. Offer, and S. Brotherstone. 2008. Risk factors and milk yield losses associated with lameness in Holstein-Friesian dairy cattle. Animal 2:1230-1237.
Ott, S. L., A. H. Seitzinger, and W. D. Hueston. 1995. Measuring the national economic-benefits of reducing livestock mortality. Prev. Vet. Med. 24:203-211.

Pastell, M., H. Takko, H. Grohn, M. Hautala, V. Poikalainen, J. Praks, I. Veermäe, M. Kujala, and J. Ahokas. 2006. Assessing cows' welfare: Weighing the cow in a milking robot. Biosyst. Eng. 93:81-87.

Peiper, U. M., Y. Edan, S. Devir, M. Barak, and E. Maltz. 1993 Automatic weighing of dairy cows. J. Agric. Eng. Res. 56:13-24.

Pinheiro, J., D. Bates, S. DebRoy, D. Sarkar, and the R Core team. 2008. nlme: Linear and Nonlinear Mixed Effects Models. R package version $3.1-88$.

R Development Core Team. 2010. R: A Language and Environment for Statistical Computing. R Foundation for Statistical Computing, Vienna, Austria.

Ren, J., N. L. Buck, and S. L. Spahr. 1992. A dynamic weight logging system for dairy-cows. Trans. ASABE 35:719-725.

Robinson, D. L. 2005. Assessing the accuracy of modelling weight gain of cattle using feed efficiency data. Livest. Prod. Sci. 95:187-200.

Roche, J. R., J. M. Lee, K. A. Macdonald, and D. P. Berry. 2007a. Relationships among body condition score, body weight, and milk production variables in pasture-based dairy cows. J. Dairy Sci. 90:3802-3815.

Roche, J. R., K. A. Macdonald, C. R. Burke, J. M. Lee, and D. P. Berry. 2007b. Associations among body condition score, body weight, and reproductive performance in seasonal-calving dairy cattle. J. Dairy Sci. 90:376-391.

Spahr, S. L., and E. Maltz. 1997. Herd management for robot milking. Comput. Electron. Agric. 17:53-62.

van Straten, M., M. Friger, and N. Y. Shpigel. 2009. Events of elevated somatic cell counts in high-producing dairy cows are associated with daily body weight loss in early lactation. J. Dairy Sci. 92:4386-4394

van Straten, M., N. Y. Shpigel, and M. Friger. 2008. Analysis of daily body weight of high-producing dairy cows in the first one hundred twenty days of lactation and associations with ovarian inactivity. J. Dairy Sci. 91:3353-3362. 